\title{
Supervision for work with overdose and deliberate self harm patients - a psychodynamic approach
}

\author{
EmILy FinCH, Research Registrar; and Rosalind RamSAy, Registrar in Psychotherapy, \\ University College Hospital, Accident and Outpatient Building, Gower Street, \\ London WC1E 6AU
}

The anxiety of staff working alone with overdose and deliberate self harm patients can be high, and demands more recognition. In assessing and treating such patients, staff often feel that they are being required to take responsibility for someone's future in the face of an enactment of extreme despair. This article looks at one way to deal with such anxiety.

For many years, the Department of Psychological Medicine at University College Hospital, London, has adopted a psychodynamic approach. With the development of the psychotherapy service, in 1981, a psychodynamically orientated multidisciplinary supervision group meeting for an hour once a week was started for the registrars and other staff who routinely assess and manage overdose and deliberate self harm patients. In spite of cuts in the service, the group has continued to flourish and still retains its important role in the department.

The hospital serves an inner city catchment area with a large population of young and homeless people. Many of the patients seen in the department have little family support, and psychiatric, psychotherapy and social services often feel unable to meet their needs. The incidence of personality disorders, sexual abuse, alcohol and drug related problems, and chronic psychotic illnesses in this group is high.

The patients may provoke a variety of responses in the professionals assessing them. Those with a diagnosis of personality disorder often induce a sense of hopelessness in the countertransference which in turn may result in a negative and cynical response from the professional. As a result, the patient may end up being offered no help and gives up, so confirming his or her feelings of hopelessness and impotence.The more trivial overdose patients, who are sometimes diagnosed as having a reactive depression, may promote a collusive response. They deny the seriousness of their suicidal intent and the professional may too easily agree. Suicide represents a profound loss of hope; it may be the tip of an iceberg in a profoundly disturbed person and needs to be understood as a loss of control over his or her feelings of self hatred. We may not know the unconscious meaning of the suicidal action but can always look at the mechanism and implications of self harm. Our task is to allow patients emotional rather than physical expression of their emotional pain. Better understanding of suicidal behaviour will help staff to make maximum use of assessment interviews and enable the patients to express anxieties about themselves in words and accept the need for psychotherapeutic intervention.

The group attempts to look at the patients' problems in a developmental context and to understand transference and countertransference issues that arise with the assessor. This encourages greater insight into the difficult feelings assessors may experience towards them. Members of the group are encouraged to discuss what help may be appropriate to the needs of their patients and not to assume that any intervention will be a useless exercise, likely to be rejected. It is helpful for the staff to know that if they can understand the reality of a patient's action and break through the denial of its importance, his or her attitude may start to change, even at a single interview. The suicidal action must be worked through before the individual is safe not to rely on it as a defence in fantasy. Even if he or she does not immediately engage in therapy, such an interview may facilitate attempts to seek help later.

The following case report illustrates some of these points.

\section{Case report}

John was a 22-year-old who was brought to Casualty following an overdose of phenytoin, paracetamol and alcohol. He required treatment with Parvolex. On psychiatric assessment he claimed that this was his 70th overdose, but in fact, our records indicated that he had only made five previous attempts to harm himself. After the last one, six months before, he had been discharged with no psychiatric follow-up.

He originally came from the North of England. His parents were separated and he described a poor relationship with each of them. He had twice been admitted to an adolescent unit and afterwards spent two years in a detention centre. He had a history of alcohol abuse and aggressive behaviour. This recent overdose had been precipitated by eviction from his hostel following a violent incident.

John looked younger than his age, and was pleasant and cooperative. He was mildly depressed, felt very hopeless 
and expressed suicidal thoughts. There were no biological features of depression. The initial diagnosis was of an unspecified personality disorder.

We helped him find bed and breakfast accommodation. However, three days later we learnt that he had been evicted. He returned to Out-patients again; on the first occasion he cut his wrists in the waiting area, but, perhaps surprisingly, did engage in treatment and later came to accept referral to the Day Hospital.

This was a young man who provoked feelings of hopelessness and futility in anyone who tried to help him; all previous interventions had been rejected or sabotaged by him. Presentation of his case to the group helped the social worker who had seen him to understand some of the reactions stemming from those feelings in herself and to recognise that this man could not deal with being alone al day even if he was given bed and breakfast accommodation. He was now offered additional psychological support that was more appropriate to his needs.

\section{Comment}

This multidisciplinary supervision group has encouraged a wide ranging approach going beyond the medical psychiatric diagnostic model. Although the patients have been traumatised, the interview allows an opportunity to intervene at a time of acute crisis when both the acuteness and the crisis are being denied by the patient. Within the group overall emphasis is given to understanding an individual's experiences of his or her situation within a broadly psychodynamic developmental model, rather than merely arriving at the correct psychiatric diagnosis and disposal.

At another level, the group has assisted in facilitating practical communication between members of the team allowing them to make maximum use of their different areas of expertise. The group has also functioned as a ward round, providing fuller coverage of the overdose service. As a result, our scarce resources have been shared and patients get maximum benefit from them. Breaking down interprofessional barriers has helped to prevent rivalries emerging between different staff members. The group has also contributed to the working relationship of the liaison service with medical and casualty staff who appreciate their patients being contained and not rejected.

Taking these patients seriously when they come into hospital has given us an opportunity to intervene at a time of crisis which might not otherwise be possible, however much in need of help a person may be. The group may help us to prevent the development of more serious problems in these vulnerable patients.

\section{Acknowledgement}

We would like to thank Consultant Psychotherapist, Dr Peter Shoenberg, and members of the group, in particular, the current leader and founder Egle Laufer, and fellow member Dr Tim Read for their comments.

\section{Expert opinion}

\section{Alprazolam and panic disorder}

In May 1988, the greater part of an issue of Archives of General Psychiatry was given over to reports of the results of a clinical trial of alprazolam for panic disorder. More recently, in March 1991, supplement no 365, of Acta Psychiatrica Scandinavica (APS) was devoted to a further trial of alprazolam for panic disorder. Few other psychotropic compounds have received such concentrated coverage. What, if anything, emerges from the studies reported?

Very little it would seem. Both sets of studies use a profusion of rating scales and statistical techniques. Both analyse in detail the trends in various sub-scales 